\title{
Examination of the Community Multiscale Air Quality (CMAQ) model performance over the North American and European domains
}

\author{
K. Wyat Appel ${ }^{\mathrm{a},{ }^{*}}$, Charles Chemel ${ }^{\mathrm{b}, \mathrm{c}}$, Shawn J. Roselle ${ }^{\mathrm{a}}$, Xavier V. Francis ${ }^{\mathrm{c}}$, Ranjeet S. Sokhi ${ }^{\mathrm{c}}$,
} S.T. Rao ${ }^{\mathrm{a}}$ and Stefano Galmarini ${ }^{\mathrm{d}}$

${ }^{a}$ Atmospheric Modeling and Analysis Division, National Exposure Research Laboratory, Office of Research and Development, United States

Environmental Protection Agency, RTP, NC, USA

${ }^{\mathrm{b}}$ National Centre for Atmospheric Science, Centre for Atmospheric \& Instrumentation Research, University of Hertfordshire, Hatfield, UK

${ }^{\mathrm{c}}$ Centre for Atmospheric \& Instrumentation Research, University of Hertfordshire, Hatfield, UK ${ }^{\mathrm{d}}$ Joint Research Center, Institute for Environment and Sustainability, Ispra, Italy

*Corresponding author: Tel: +1 919541 0757; fax: +1 919541 1379. E-mail:

appel.wyat@epa.gov. U.S. EPA-E243-04, Research Triangle Park, NC, 27711 USA

For submission to the Atmospheric Environment special issue on the AQMEII project 


\section{Abstract}

3 The CMAQ modeling system has been used to simulate the air quality for North America and

4 Europe for the entire year of 2006 as part of the Air Quality Model Evaluation International

5 Initiative (AQMEII) and the operational model performance of $\mathrm{O}_{3}$, fine particulate matter

$6 \quad\left(\mathrm{PM}_{2.5}\right)$ and $\mathrm{PM}_{10}$ for the two continents assessed. The model underestimates daytime (8am -

7 8pm LST) $\mathrm{O}_{3}$ mixing ratios by $13 \%$ in the winter for North America, primarily due to an

8 underestimation of daytime $\mathrm{O}_{3}$ mixing ratios in the middle and lower troposphere from the lateral

9 boundary conditions. The model overestimates winter daytime $\mathrm{O}_{3}$ mixing ratios in Europe by an

10 average of $8.4 \%$. The model underestimates daytime $\mathrm{O}_{3}$ by $4-5 \%$ in the spring for both

11 continents, while in the summer daytime $\mathrm{O}_{3}$ is overestimated $(\mathrm{NMB}=9.8 \%)$ for North America

12 but only slightly underestimated $(\mathrm{NMB}=-1.6 \%)$ for Europe. The model overestimates daytime

$13 \mathrm{O}_{3}$ in the fall for both continents, grossly overestimating daytime $\mathrm{O}_{3}$ by over $30 \%$ for Europe.

14 The performance for $\mathrm{PM}_{2.5}$ varies both seasonally and geographically for the two continents. For

15 North American, $\mathrm{PM}_{2.5}$ is overestimated in the winter and fall, with an average NMB greater

16 than $-30 \%$, while performance in the summer is relatively good, with an average NMB of $-4.6 \%$.

17 For Europe, $\mathrm{PM}_{2.5}$ is underestimated throughout the entire year, with the NMB ranging from -

$1824 \%$ in the fall to $-55 \%$ in the winter. $\mathrm{PM}_{10}$ is underestimated throughout the year for both North

19 America and Europe, with remarkably similar performance for both continents. The domain

20 average $\mathrm{NMB}$ for $\mathrm{PM}_{10}$ ranges between $-45 \%$ and $-65 \%$ for the two continents, with the largest

21 underestimation occurring in the summer for North American and the winter for Europe. 
23 Keywords: CMAQ; Ozone; Particulate Matter; Air Quality Modeling; Model Evaluation;

\section{AQMEII}

25

26 2006.

\section{Introduction}

The Air Quality Model Evaluation International Initiative (AQMEII) is a model evaluation effort involving numerous research groups from North American and Europe with the goal of advancing the methods for evaluating regional-scale air quality modeling systems. As part of the AQMEII project, the Community Multiscale Air Quality (CMAQ; Foley et al., 2010) model has been applied to simulate air quality over North America (NA) and Europe (EU) for the year

The CMAQ simulation performed for NA for this project is unique compared to the CMAQ simulations performed in the past for several reasons. First, the simulation was performed over a single domain that covers the entire CONUS and a large portion of Canada using $12-\mathrm{km}$ by $12-\mathrm{km}$ horizontal grid spacing. In the past, two separate simulations covering the eastern and western U.S. have been used instead of single, continuous domain. Second, the simulation utilizes meteorology provided by the latest version of the Weather Research and Forecasting (WRF) model, whereas previous CMAQ annual simulations have typically utilized meteorology provided by the $5^{\text {th }}$ Generation Mesoscale Model (MM5; Grell et al., 1994).

Finally, the CMAQ simulation utilizes boundary conditions provided by the Global and regional Earth-system Monitoring using Satellite and in-situ data (GEMS) product.

The analysis presented here focuses primarily on ozone $\left(\mathrm{O}_{3}\right)$ and particulate matter $\left(\mathrm{PM}_{2.5}\right.$ and $\mathrm{PM}_{10}$ ), as these are pollutants for which both the NA and EU have established criteria for 
47 acceptable limits (e.g. National Ambient Air Quality Standards) and instituted numerous control

48 strategies to reduce precursor emissions. The analysis presented here is intended to provide a

49 broad overview of the operational performance of the CMAQ model for these pollutants for NA

50 and EU, and compare and contrast significant similarities or differences in model performance

51 for the two continents.

53 2. Data

$54 \quad 2.1$ Model Inputs and Configuration

The CMAQ model requires gridded meteorological and emissions data to simulate the

57 formation, transport and fate of numerous atmospheric pollutants, including $\mathrm{O}_{3}$ and $\mathrm{PM}$.

58 Meteorological data for the NA and EU simulations were provided by the Weather Research and

59 Forecast (WRF) model (Skamarock et al., 2008). For NA, the WRF domain covered the

60 CONUS and portions of Canada and Mexico using 12-km by 12-km horizontal grid spacing and

61 34-vertical layers extending up to $50 \mathrm{hPa}$. The simulation utilized the Pleim-Xu land surface

62 model (LSM), ACM2 planetary boundary layer (PBL) scheme, Morrison mixed phase (MP)

63 scheme, Kain-Fritsch2 cumulus parameterization (CuP) scheme and the RRTMG long-wave

64 radiation (LWR) scheme. Lateral boundary conditions (BCs) were provided by the North

65 American Model (NAM), available from the National Centers for Environmental Prediction.

For the EU CMAQ simulation, the WRF model was also used, but with a slightly

67 different configuration to that of the NA WRF simulation more appropriate for simulating the

68 Europe continent. The EU WRF simulation was performed using $18-\mathrm{km}$ by $18-\mathrm{km}$ horizontal

69 grid spacing with 52 vertical layers, 11 of which were below 1-km. The simulation utilized the 
NOAH LSM, Morrison (MP) scheme, Grell and Devenyi CuP scheme, and RRTMG LWR

71 scheme. Initial and lateral BCs were provided by the European Center for Medium-Range

72 Weather Forecasts (ECMWF) model. Outputs from the WRF simulations for both continents

73 were preprocessed for input into CMAQ using v3.6 of the Meteorology-Chemistry Interface

74 Processor (MCIP; Otte et al., 2005). More specific details regarding the WRF simulations,

75 including references for the various schemes used and an operational performance evaluation of

76 the simulations can be found in Vautard et al. (this issue).

77 The NA CMAQ model simulation used the AQMEII standard NA emissions dataset,

78 which is based on a 12-km national U.S. domain with speciation for the Carbon-Bond 05 (CB05)

79 chemical mechanism (Yarwood et al., 2005). The emission inventory and ancillary files were

80 based on the 2005 emission modeling platform. The fire emissions were based on 2006 daily

81 fire estimates using the Hazard Mapping System Fire detections and Sonoma Technology

82 SMARTFIRE system. Continuous Emission Monitoring System (CEMS) data from 2006 was

83 used for the electric generating units sector. Plume rise was calculated within the CMAQ model

84 (in-line). Temporal allocation was done monthly for each day of the week with all holidays

85 ignored. Emissions were preprocessed for the CMAQ model using the Sparse Matrix Operator

86 Kernel Emissions (SMOKE; Houyoux et al., 2000).

87 The AQMEII standard EU emissions data were used for the EU CMAQ simulation and

88 are based on the TNO (http://www.tno.nl/) inventory for 2005, which consists of anthropogenic

89 emission from ten Selected Nomenclature for Air Pollution (SNAP) sectors and international

90 shipping. The ten SNAP sectors are energy transformation, small combustion sources, industrial

91 combustion, industrial processes, extraction of fossil fuels, solvent and product use, road

92 transport, non road transport, waste handling, and agriculture. Biogenic emissions of isoprene 
93 and terpene, calculated using the Model of Emissions of Gases and Aerosols from Nature

94 (MEGAN; Guenther and Wiedinmyer, 2007; Sakulyanontvittaya et al., 2008), are included on

95 the same resolution as the anthropogenic emissions. The fire emissions were bases on 2006 daily

96 fire estimates from the MODIS fire radiative power product using the FMI Fire Assimilation

97 System FAS-FRP (Sofiev et al., 2009). Plume rise was calculated offline with SMOKE. A more

98 detailed description of the emission used for the two continents is available in Pouliot et al. (this

99 issue).

The CMAQ model configurations were similar for NA and EU, with both simulations

101 utilizing version 4.7.1 (Foley et al., 2010) of the model. The NA simulation used 34-vertical

102 layers (matched to the WRF model vertical layers) and 12-km horizontal grid spacing covering

103 the CONUS, southern Canada and northern Mexico, while the EU simulation used 34 vertical

104 layers (52 WRF vertical layers collapsed to 34 CMAQ vertical layers in MCIP) and 18-km

105 horizontal grid spacing covering most of EU. Other model options employed that were common

106 to both simulations include the CB05 chemical mechanism with chlorine chemistry extensions

107 (Yarwood et al., 2005), the AERO5 aerosol module (Carlton et al, 2010), the Asymmetric Cloud

108 Model 2 (ACM2) PBL scheme (Pleim, 2007a,b).

Both the NA and EU simulations utilized the standard AQMEII BCs provided by the

110 Global and regional Earth-system Monitoring using Satellite and in-situ data (GEMS) product

111 (http://gems.ecmwf.int/about.jsp), which assimilates modeled data and observations (surface and

112 satellite) to provide data for meteorology and atmospheric gases including greenhouse gases,

113 global reactive gases and global aerosols. A more detailed description of the GEMS data as used

114 as boundary conditions can be found in Schere et al. (this issue). 
For NA the observed data used to assess the CMAQ model estimates are obtained from

119 several observational networks available across the U.S. that measure a combination of gas, 120 aerosol, wet deposition and meteorological variables. The primary sources of ground level $\mathrm{O}_{3}$,

$121 \mathrm{PM}_{2.5}$ and $\mathrm{PM}_{10}$ mass measurements for the U.S. is the USEPA's Air Quality System (AQS). The

122 AQS network is geographically diverse and spans the entire U.S. and is an excellent source of

123 quality assured air quality measurements. Measurements of $\mathrm{O}_{3}$ are hourly, while measurements

124 of PM can be either hourly or daily averages (available every 1, 3 or 6 days), depending on the

125 particular site configuration. For observations of $\mathrm{PM}_{2.5}$, measurements from the AQS, the

126 Chemical Speciation Network (CSN) and the Interagency Monitoring of Protected Visual

127 Environments (IMPROVE) network are used. In additional to total $\mathrm{PM}_{2.5}$, the CSN and

128 IMPROVE networks provide measurements of particulate $\mathrm{SO}_{4}{ }^{2}, \mathrm{NO}_{3}{ }^{-}, \mathrm{NH}_{4}{ }^{+}, \mathrm{EC}$ and $\mathrm{OC}$, along

129 with a large number of other trace elements. The AQS is used to provide $\mathrm{PM}_{10}$ measurement

130 data. For Canada, the National Air Pollution Surveillance (NAPS) network provides

131 measurements of $\mathrm{O}_{3}$ and $\mathrm{PM}_{2.5}$.

132 The air quality networks in EU used to provide data for the present analysis are the

133 AirBase network (http://www.eea.europa.eu/themes/air/airbase), the Automatic Urban and Rural

134 (AURN; http://uk-air.defra.gov.uk/interactive-map) network and the EMEP

135 (http://www.emep.int/index_facts.html) network. Each of these networks provides hourly and 136 daily average data for a number species, including $\mathrm{O}_{3}, \mathrm{PM}_{2.5}$ and $\mathrm{PM}_{10}$. Assessment of the model

137 performance was accomplished using the Atmospheric Model Evaluation Tool (AMET; Appel et 138 al., 2010), which can perform a vast number of different analyses and produce many different 
139 plots useful for assessing model performance. AMET was originally designed for the U.S. based

140 air quality networks, but has been extended to incorporate observations available from air quality

141 networks in EU.

142

143 3. Results

1443.1 Ozone

Ozone is an important criteria pollutant for both NA and EU. Ozone mixing ratios are

147 the highest in the summer as the production of $\mathrm{O}_{3}$ is a photo-chemically driven reaction and the

148 reactions are more efficient under higher temperatures. In the U.S., $\mathrm{O}_{3}$ mixing ratios generally

149 peak in July and August (Fig. 1), when temperatures are the highest and the sun angle is high.

150 The pattern of $\mathrm{O}_{3}$ mixing ratios in $\mathrm{EU}$ is similar to that of $\mathrm{NA}$, with a peak in $\mathrm{O}_{3}$ mixing ratios in

151 June and July (Fig. 2). The current daily thresholds for $\mathrm{O}_{3}$ in the U.S. and EU are based on the

152 maximum daily 8 -hr average $\mathrm{O}_{3}$ value and are currently set to $75 \mathrm{ppb}$ for the U.S. and $120 \mu \mathrm{gm}^{-3}$

153 ( $\sim 60 \mathrm{ppb})$ for EU. Since the $\mathrm{O}_{3}$ standards for each continent are based on the daily maximum 8-

$154 \mathrm{hr}$ average $\mathrm{O}_{3}$, the analysis here is limited to just the daytime hours, where daytime is defined as

155 8am to 8pm local standard time (LST), when $\mathrm{O}_{3}$ mixing ratios are the highest.

156 For NA, operational model performance for $\mathrm{O}_{3}$ was generally consistent with previous

157 CMAQ simulations (Eder and Yu, 2006; Tesche et al., 2006; Appel et al., 2007), with several

158 notable exceptions. Performance of maximum 8-hr average $\mathrm{O}_{3}$ in the winter (January - March)

159 underperformed previous CMAQ simulations (Appel et al., 2007), with the model demonstrating

160 a large underestimation of daytime $\mathrm{O}_{3}(-13.4 \%$ domain-wide average) for that period (Table 1).

161 Fig. 1 illustrates the large underestimation of $\mathrm{O}_{3}$ for $\mathrm{NA}$ in the winter, while Fig. 3a presents a 
162 spatial plot of Normalized Mean Bias (NMB) for AQS sites for winter. The underestimation of

$163 \mathrm{O}_{3}$ in the winter is largest in the Northeast and Great Lakes regions of the U.S. and for most of

164 the Canadian sites, with smaller underestimations in the southern U.S. For EU, the CMAQ

165 system overestimates daytime $\mathrm{O}_{3}$ in southwestern half of the domain and underestimates daytime

$166 \mathrm{O}_{3}$ in the northeastern half of the domain, including the United Kingdom, in the winter (Fig. 4a).

167 The largest overestimations occur in northern Italy, primarily in Po River Valley, where a large

168 number of sites have NMBs greater than 100\%. The largest underestimations occur in the Czech

169 Republic and Poland, where some sites have NMBs exceeding -70\%.

170 Investigation of the poor wintertime performance for $\mathrm{O}_{3}$ in the NA CMAQ simulation

171 suggests that the lateral BCs used in the AQMEII CMAQ simulation are largely responsible for

172 the poor performance (Schere et al. this issue). In order to determine the impact of the later BCs

173 on the winter $\mathrm{O} 3$ model estimates, the CMAQ simulation was repeated using BCs provided by

174 the global model GEOS-Chem (Bey et al., 2001) instead of the AQMEII default BCs which used

175 GEMS. The $\mathrm{O}_{3}$ time-series for the NA and EU CMAQ simulations using lateral BCs provided

176 by the GEOS-Chem model are presented in Figs. 1 and 2 along with the base AQMEII CMAQ

177 simulation. The large wintertime underestimation of daytime $\mathrm{O}_{3}$ that is clearly evident in

178 CMAQ simulation for NA using the GEMS derived BCs is not present in the CMAQ simulation

179 that utilized GEOS-Chem BCs. Similarly, the CMAQ estimated $\mathrm{O}_{3}$ in the simulation for EU

180 using GEOS-Chem BCs is much higher in the winter and spring than the simulation using

181 GEMS BCs.

182 Further comparison of the vertical profiles of observed and CMAQ estimated $\mathrm{O}_{3}$ (not

183 shown) indicated that the mid to lower tropospheric $\mathrm{O}_{3}$ mixing ratios in the GEMS BCs were

184 significantly underestimated, while the same comparison to the CMAQ estimated $\mathrm{O}_{3}$ from the 


\section{Draft - Do not cite or quote}

185 simulation using GEOS-Chem BCs showed no significant underestimation of lower tropospheric

$186 \mathrm{O}_{3}$ (see also Schere et al., 2011 for additional discussion of the GEMS data). The lower $\mathrm{O}_{3}$

187 mixing ratios in the troposphere in the GEMS BCs result in lower ground-level $\mathrm{O}_{3}$ mixing ratios,

188 particularly in the winter when $\mathrm{O}_{3}$ provided from the lateral boundaries contributes a significant

189 portion of the CMAQ estimated ground-level $\mathrm{O}_{3}$. In the summer, $\mathrm{O}_{3}$ mixing ratios in the lower

190 troposphere in the GEMS BCs are much more similar in magnitude to the mixing ratios in the

191 GEOS-Chem BCs, which results in better agreement with observations. Schere et al. (this issue)

192 describe similar results for a comparison between the CMAQ simulations for EU using GEMS

193 and GEOS-Chem BCs, and note that the performance degrades in the lower troposphere when

194 using the GEMS BCs.

195 For the spring, the site specific NMBs typically range between $\pm 10 \%$ for much of North

196 America, with slightly larger NMBs in the Northeast, Canada and California, where daytime $\mathrm{O}_{3}$

197 is underestimated at some sites by $20 \%$ or more (Fig. 3b). For EU, there continues to be a strong

198 differentiation in performance in the spring between the southwest and northeast portions of the

199 domain that was seen in the winter, with $\mathrm{O}_{3}$ being relatively unbiased (NMB within $\pm 10 \%$ ) in the

200 southwest (the exception being northern Italy where $\mathrm{O}_{3}$ is overestimated/underestimated by $50 \%$

201 at several sites). The daytime $\mathrm{O}_{3}$ for sites in Germany, Poland and the Czech Republic is

202 frequently underestimated by $10-30 \%$ in the spring (Fig. 4b). Similar to the simulation for NA, a

203 contributing factor to the underestimation of $\mathrm{O}_{3}$ in the spring is the underestimation of $\mathrm{O}_{3}$ in the

204 GEMS lateral BCs (see Schere et at. in this issue).

205 For the summer, daytime $\mathrm{O}_{3}$ is overestimated over the majority of NA (domain average

$206 \mathrm{NMB}=9.8 \%$ ), with the largest overestimations in California, Florida and along the Gulf of

207 Mexico (Fig. 3c). The NMB for the Canadian NAPS sites in summer tends to be lower than that 
208 of the AQS sites. For EU, the daytime $\mathrm{O}_{3}$ performance is generally better than that of NA, with a

209 large number of sites having NMBs within $\pm 10 \%$ and the majority of sites having NMBs with

$210 \pm 20 \%$ (Fig. 4c). The largest biases occur in France and northern Italy (Po River Valley), where

$211 \mathrm{O}_{3}$ tends to be underestimated by $10-20 \%$ for the majority of the sites, and along the coast of

212 Spain, where the model typically overestimates daytime $\mathrm{O}_{3}$ by $20 \%$ or more (slightly smaller

213 overestimations occur along the coast of Italy as well). The overestimation of $\mathrm{O}_{3}$ in the summer

214 along coastal areas is seen in the CMAQ simulation for NA as well (Fig. 3c), suggesting that the

215 source of the large biases may be due to errors in the meteorological inputs to the CMAQ

216 system, particularly in regards to the meteorological model's ability to accurately represent the

217 sea-breeze and land-breeze effects along the coast. The CMAQ model performance for the

218 summer is consistent with a previous study by Eder et al. (2009) that reported CMAQ

219 overestimated $\mathrm{O}_{3}$ during the summer by about $9 \%$ and also noted very large overestimations

220 along the Gulf of Mexico.

221 Daytime $\mathrm{O}_{3}$ is overestimated in the fall for both NA and EU (Figs. 3d and 4d). The

222 largest overestimations in NA occur in the eastern U.S. (including the eastern NAPS sites),

223 where the NMB frequently exceed $20 \%$ at a large number of sites, and in the Northwest, where

224 the NMB exceeds $80 \%$ at several of the NAPS sites. The fall has the worst overall performance

225 for daytime $\mathrm{O}_{3}$ for $\mathrm{EU}$, with the model grossly overestimating $\mathrm{O}_{3}$ across most of the domain

226 (domain average $\mathrm{NMB}=32.3 \%$ ). The majority of sites have NMBs greater than $20 \%$, with a

227 large number of sites in northern Italy having NMBs exceeding 100\%.

$229 \quad 3.2 P M_{2.5}$ 
$232 \mathrm{PM}_{10}$ with a diameter less than $10 \mu \mathrm{m}$, is an important air pollutant for which standards exist for

233 both the U.S. and EU. The U.S. limits on PM are based on $\mathrm{PM}_{2.5}$, with the current annual limit

234 set at $15 \mu \mathrm{gm}^{-3}$, while for EU the primary PM standard is based on $\mathrm{PM}_{10}$, with the current annual

235 limit set at $40 \mu \mathrm{gm}^{-3}$. Since the two continents use different standards for regulating PM, the

236 monitoring networks are also different, with North American (U.S. and Canada) networks

237 focused primarily on measuring $\mathrm{PM}_{2.5}$ and European networks focused on measuring $\mathrm{PM}_{10}$. As

238 such, $\mathrm{PM}_{10}$ measurements for $\mathrm{NA}$ are not as widely available as $\mathrm{PM}_{2.5}$ measurements, and

239 likewise there are limited $\mathrm{PM}_{2.5}$ measurements available for EU. On average, there are

240 approximately 870 AQS sites in the U.S. and 160 AirBase sites in EU with $\mathrm{PM}_{2.5}$ measurements,

241 and 580 AQS sites and over 1000 AirBase sites with $\mathrm{PM}_{10}$ measurements.

242 Unlike $\mathrm{O}_{3}$, which has a large seasonal dependency, $\mathrm{PM}_{2.5}$ concentrations in NA do not

243 vary as much throughout the year (Fig. 5), while for EU high concentrations of $\mathrm{PM}_{2.5}$ are

244 observed from January through March, after which the concentrations are considerably lower

245 and relatively constant throughout the remainder of the year (Fig. 6). The CMAQ model

246 generally does well representing the small seasonal trends in $\mathrm{PM}_{2.5}$ for both continents, and

247 captures the synoptic forcing features. Note that there are a limited number of $\mathrm{PM}_{2.5}$

248 observations available for EU, with the majority of the observations sites in Portugal, Spain,

249 France, Italy, Belgium, Germany, and the Czech Republic.

250 For the winter, there is a large overestimation of $\mathrm{PM}_{2.5}$ in NA (Table 2), with a domain251 wide average NMB of $30.4 \%$ and Mean Bias (MB) of $3.4 \mu \mathrm{gm}^{-3}$, but underestimates $\mathrm{PM}_{2.5}$ to an

252 even greater extent in $\mathrm{EU}$, with a NMB of $-55 \%\left(\mathrm{MB}=-12.9 \mu \mathrm{gm}^{-3}\right)$. The largest

253 underestimations in the NA occur in the west, where a large number of sites report NMBs greater 
254 than $100 \%$ (Fig. 7a). The northeastern U.S. also has a number of sites with NMBs exceeding

$25530 \%$. For EU, the underestimation in $\mathrm{PM}_{2.5}$ is systematic across the domain, with only a handful

256 of sites reporting an overestimation (Fig. 8a). The largest underestimations occur in the Czech

257 Republic, Germany and Italy, with the majority of sites reporting NMBs greater than $-60 \%$. The 258 performance for France, the United Kingdom, Spain and Portugal is better, with a number of 259 sites reporting NMBs smaller than $-30 \%$.

260 The overestimation in $\mathrm{PM}_{2.5}$ in NA is primarily due to an overestimation of the 261 unspeciated $\mathrm{PM}_{2.5}$ mass, along with a smaller overestimation of elemental and organic carbon 262 (Appel et al, 2008). The unspeciated $\mathrm{PM}_{2.5}$ mass, sometimes referred to as $\mathrm{PM}_{\mathrm{other}}$, is comprised 263 primarily of the non-carbon atoms associated with OC, along with trace elements (e.g. Fe, $\mathrm{Mg}$, 264 Mn, etc.), primary ammonium and other unidentified mass in the speciation profiles. Since this 265 unspeciated mass makes up a significant portion of the total $\mathrm{PM}_{2.5}$ mass and is often largely 266 under or overestimated in the CMAQ model, efforts were made to include speciation of the 267 unidentified mass, in particular the trace elements, in the model. The next version of the CMAQ 268 model, due to be released in the fall of 2011, will include the speciation of the trace metals, 269 allowing for a comparison of the model estimates to observations, which will hopefully lead to 270 an improvement in the model estimates for those elements and reduction in the bias for PM $\mathrm{other}_{\text {. }}$ 271 The model estimates for $\mathrm{PM}_{2.5}$ improve significantly in the spring, with a domain-wide 272 average NMB of $18.9 \%\left(\mathrm{MB}=2.0 \mu \mathrm{gm}^{-3}\right)$ for $\mathrm{NA}$ and $-36.9 \%\left(\mathrm{MB}=-5.8 \mu \mathrm{gm}^{-3}\right)$ for EU (Table 273 2). For NA, $\mathrm{PM}_{2.5}$ tends to be underestimated in the southern portion of the domain, with most 274 sites having a NMB less than $-20 \%$, while $\mathrm{PM}_{2.5}$ continues to be overestimated by the model in 275 the Northeast and in the west, where most sites have a NMB of $20 \%$ or greater (Fig. 7b). For 276 EU, $\mathrm{PM}_{2.5}$ continues to be significantly underestimated in the east (Czech Republic and Italy), 
277 with the underestimation in Germany, France and the United Kingdom improved from the winter

278 (Fig. 8b). The performance in Spain and Portugal is relative good, with most sites having a

279 NMB within $\pm 20 \%$.

280 For the summer, CMAQ estimated $\mathrm{PM}_{2.5}$ concentrations are slightly underestimated on 281 average, with a domain-wide average NMB of $-4.6 \%$ and MB of $-0.6 \mu \mathrm{gm}^{-3}$ (Table 2). Spatially, $282 \mathrm{PM}_{2.5}$ is underestimated by $20-30 \%$ for majority of sites in the eastern U.S., the exceptions being 283 Florida, where $\mathrm{PM}_{2.5}$ is overestimated, and the Great Lakes region, where most sites have NMBs 284 within $\pm 10 \%$ (Fig. 7c). The underestimations in the southeastern U.S. may be due in part to an 285 underestimation of secondary organic aerosol, which can make up a large portion of the total $286 \mathrm{PM}_{2.5}$ in the southeast (Carlton et al., 2010). Large underestimations of $\mathrm{PM}_{2.5}$ in the desert 287 Southwest (New Mexico, Arizona, Colorado and Utah) of $-50 \%$ or more may be due to a lack of 288 wind-blown dust in the model. The next version of the CMAQ model will include a method for 289 representing wind-blown dust, which may improve the underestimations of $\mathrm{PM}_{2.5}$ in the 290 southwestern U.S. in the summer. For EU, the performance for the summer is similar to the 291 spring, with a domain-wide average NMB of $-37.2 \%\left(\mathrm{MB}=-4.9 \mu \mathrm{gm}^{-3}\right)$, and a similar spatial 292 distribution of bias as the spring (Fig. 8c).

293 For the fall, $\mathrm{PM}_{2.5}$ is again overestimated for NA, with a domain-wide average NMB of $29436.3 \%\left(\mathrm{MB}=4.0 \mu \mathrm{gm}^{-3}\right)$. The spatial pattern of bias is similar to that of the winter, with the 295 largest overestimations in the northeast and northwest U.S. (Fig. 7d). As with the winter, the 296 overestimation of the unspeciated $\mathrm{PM}_{2.5}$ mass is largely responsible for the overestimation of $297 \mathrm{PM}_{2.5}$ in the fall, along with smaller overestimations of particle nitrate and ammonium. For EU, $298 \mathrm{PM}_{2.5}$ continues to be underestimated, however the bias is smaller than any of the other seasons, 299 with an average NMB of $-24.2 \%\left(\mathrm{MB}=-3.8 \mu \mathrm{gm}^{-3}\right)$. The largest underestimations continue to 
300 be in the Czech Republic and Italy, with most sites having NMBs of $-20 \%$ to -50\% (Fig. 8d).

301 Performance for sites in Germany, France the United Kingdom improves again, with most sites

302 having NMBs within $\pm 20 \%$, while in Spain and Portugal several of the sites now show an

303 overestimation of $\mathrm{PM}_{2.5}$, generally within $30-50 \%$.

The $\mathrm{PM}_{10}$ mass is composed of all the PM less than $10 \mu \mathrm{m}$ in diameter, and therefore

308 includes all the $\mathrm{PM}_{2.5}$ mass and coarse $\mathrm{PM}\left(\mathrm{PM}_{10^{-}} \mathrm{PM}_{2.5}\right)$. Fig. 9 presents the domain-average

309 time series for observed and CMAQ estimated $\mathrm{PM}_{10}$ for NA, while Fig. 10 presents a similar

310 time-series plot for EU. The model systematically underestimates $\mathrm{PM}_{10}$ for both continents

311 throughout the year, with the largest underestimation occurring in the winter for EU when

312 observed $\mathrm{PM}_{10}$ is very high. For EU in the winter, the domain average NMB is $-64.8 \%(\mathrm{MB}=-$

$\left.31321.5 \mu \mathrm{gm}^{-3}\right)$, compared to only $-47.6 \%\left(\mathrm{MB}=-11.5 \mu \mathrm{gm}^{-3}\right)$ for NA. For the other seasons, the

314 underestimation for both continents is nearly identical and relatively consistent through the year,

315 with the model underestimating $\mathrm{PM}_{10}$ by between $45-60 \%\left(11-16 \mu \mathrm{gm}^{-3}\right)$ for each continent

316 (Table 3).

317 Spatially, the model tends to demonstrate a similar bias pattern throughout the year for

318 both continents. In the winter, when the $\mathrm{PM}_{10}$ underestimation is the smallest for NA, the model

319 generally overestimates $\mathrm{PM}_{10}$ by $20-50 \%$ along the east coast of the U.S. (Fig. 11a). For the rest

320 of country, $\mathrm{PM}_{10}$ is largely underestimated, particularly in the western U.S. (with the exception

321 of areas right along the coast). For EU, almost every site shows an underestimation of $\mathrm{PM}_{10}$,

322 with most sites having NMBs exceeding $-50 \%$ (Fig. 12a). The smallest biases are in northern 
323 France, where most sites have NMBs less than 30\%. In the spring, the bias pattern is similar to

324 the winter, with the smallest biases for NA occurring along the east and west coasts, while in EU 325 the bias spatial pattern is nearly identical to that of winter (Figs. 11b and 12b).

326 For the summer, the majority of sites in NA now show some level of underestimation of

$327 \mathrm{PM}_{10}$, with almost all the sites in the western U.S. having NMBs greater than -20\% (Fig. 11c).

328 For EU, the bias pattern is again similar to the winter and spring, with only northern France and

329 Portugal having any significant number of sites showing NMBs smaller than 40\% (Fig. 12c).

330 The bias tends to improve in the fall for both continents compared to the summer, with a large

331 number of sites in the eastern U.S. having NMBs between $\pm 30 \%$, while in the western U.S. most

332 sites continue to show large underestimations of $\mathrm{PM}_{10}$ of $50 \%$ or more (Fig. 11d). For EU, the

333 majority of sites continue to show significant underestimations of $\mathrm{PM}_{10}$ in the fall (Fig. 12d),

334 however a large number of sites in France and Germany now have NMBs between -20 to -30\%,

335 an improvement of the $-40 \%$ or more NMBs seen in the other seasons. Additional analysis is

336 needed to diagnose the cause for the large biases in CMAQ PM $\mathrm{P}_{10}$ estimates, which are likely due

337 to a combination of errors in the emissions inventory and chemical transport model.

339 4. Summary

The CMAQ modeling system has been used to simulate NA and EU for the entire year of

342 2006. The model performance for $\mathrm{O}_{3}$ varies seasonally, with the model underestimating daytime

$343 \mathrm{O}_{3}$ mixing ratios in the winter by about $13 \%$ for $\mathrm{NA}$ and overestimating daytime $\mathrm{O}_{3}$ for EU by

344 roughly $8 \%$. Analysis suggests that lower $\mathrm{O}_{3}$ mixing ratios in the middle and lower troposphere

345 from the chemical boundary conditions are primarily responsible for the lower ground-level $\mathrm{O}_{3}$ 
346 mixing ratios in the winter in $\mathrm{NA}$ and EU. For the spring, daytime $\mathrm{O}_{3}$ is slightly underestimated

347 for both NA and EU (4-5\%), likely due in part to an underestimation of $\mathrm{O}_{3}$ from the boundaries.

348 For the summer, when $\mathrm{O}_{3}$ mixing ratios are the highest, CMAQ overestimates daytime $\mathrm{O}_{3}$ for

349 NA by about $10 \%$ on average, while for EU the model underestimates daytime $\mathrm{O}_{3}$ by less than

$3502 \%$ on average. Daytime $\mathrm{O}_{3}$ continues to be overestimated in the fall for NA by $8 \%$ on average,

351 while for the EU the model grossly overestimates $\mathrm{O}_{3}$ by more than $30 \%$ on average. Overall, the

352 model demonstrates relatively similar performance for daytime $\mathrm{O}_{3}$ in both modeling domains,

353 with the exception of the fall.

354 The model performance for $\mathrm{PM}_{2.5}$ varies between the two continents, with the model

355 overestimating $\mathrm{PM}_{2.5}$ in the winter, spring and fall, and being relatively unbiased in the summer

356 for NA, while for EU the model underestimates $\mathrm{PM}_{2.5}$ throughout the entire year. While it is not

357 clear what is driving the bias in $\mathrm{PM}_{2.5}$ for the two continents, likely sources of error for both

358 continents is the lateral boundary conditions and emissions. It would be helpful to examine any

359 speciated $\mathrm{PM}_{2.5}$ data available in EU to determine what components of $\mathrm{PM}_{2.5}$ are primarily

360 responsible for the underestimation. The model performance for $\mathrm{PM}_{10}$ was also examined for

361 both continents, with the model systematically underestimating $\mathrm{PM}_{10}$ for both continents.

362 Outside of the winter months, when $\mathrm{PM}_{10}$ was grossly underestimated for EU, the model

363 performance for $\mathrm{PM}_{10}$ for both continents is very similar, with model generally underestimating

$364 \mathrm{PM}_{10}$ between $45-60 \%$ on average. More investigation is needed to determine what is driving

365 the poor $\mathrm{PM}_{10}$ estimates from the modeling system (e.g. emissions or meteorology). Segregating

366 the data by different synoptic regimes (e.g. Appel et al., 2007) may highlight the role

367 meteorology plays in the $\mathrm{PM}_{10}$ estimates, while the addition of trace metals and a method for 
368 tracking wind-blown dust available in the next release of the CMAQ model may help illuminate

369 errors in the emission inventory.

370 The analysis presented here represents only a broad overview of the operational model

371 performance of three pollutants for NA and EU. The analysis describes some the similarities and

372 differences in model performance between the two continents and highlights aspects of the

373 modeling system that need improvement (e.g. $\mathrm{PM}_{10}$ ). Further analysis is needed to determine the

374 factors driving these differences in model performance. Future work will include comparing the

375 model performance for other species, such as $\mathrm{NO}_{2}$ and $\mathrm{SO}_{2}$, between the two continents, as well

376 as examining the performance of the model wet deposition estimates, which are important

377 outputs used in ecological studies.

378

379 Acknowledgements

381 We gratefully acknowledge the contributions of various groups to the first Air Quality

382 Model Evaluation International Initiative (AQMEII) activity. The following agencies have

383 prepared the datasets used in the preparation phase of this study: U.S. EPA (North American

384 emissions processing and gridded meteorology); U.S. EPA, Environment Canada, Mexican

385 Secretariat of the Environment and Natural Resources (Secretaría de Medio Ambiente y

386 Recursos Naturales-SEMARNAT), and National Institute of Ecology (Instituto Nacional de

387 Ecología-INE) (North American national emissions inventories); TNO (European emissions

388 processing); Laboratoire des Sciences du Climat et de l'Environnement, IPSL,

389 CEA/CNRS/UVSQ (gridded meteorology for Europe); and ECMWF/GEMS project and Météo-

390 France/CNRM-GAME (Chemical boundary conditions). Ambient North American 
391 concentration measurements were extracted from Environment Canada's National Atmospheric

392 Chemistry Database (NAtChem) PM database and provided by several U.S. and Canadian

393 agencies (AQS, CAPMoN, CASTNet, IMPROVE, NAPS, SEARCH, and STN networks); North

394 American precipitation-chemistry measurements were extracted from NAtChem's precipitation-

395 chemistry database and were provided by several U.S. and Canadian agencies (CAPMoN,

396 NADP, NBPMN, NSPSN, and REPQ networks); the WMO World Ozone and Ultraviolet Data

397 Centre (WOUDC) and its data-contributing agencies provided North American and European

398 ozonesonde profiles; NASA's Aerosol Robotic Network (AeroNet) and its data-contributing

399 agencies provided North American and European AOD measurements; the MOZAIC Data

400 Centre and its contributing airlines provided North American and European aircraft takeoff and

401 landing vertical profiles. For European air-quality data, the EMEP European Environment

402 Agency/European Topic Center on Air and Climate Change/AirBase provided European air- and

403 precipitation chemistry data. Data from meteorological station monitoring networks were

404 provided by NOAA and Environment Canada (for the U.S. and Canadian meteorological

405 network data) and the National Center for Atmospheric Research (NCAR) data support section.

406 Joint Research Center Ispra/Institute for Environment and Sustainability provided its

407 ENSEMBLE system for model-output harmonization and analyses and evaluation.

408 The authors would like to extend a special note of thanks to the Computer Sciences

409 Corporation for performing the WRF simulation, emissions processing and CMAQ model

410 simulations for North America. This work was partially supported by the University of

411 Hertfordshire under the TEMPO project awarded through its Small Research Grants

412 Competition. We would like to thank Guido Pirovano (INERIS, France and RSE, Milan, Italy)

413 for his help in setting up AMET for Europe. 


\section{Draft - Do not cite or quote}

414

415 The views expressed here are those of the authors and do not necessarily reflect the views

416 and policies of the U.S. Environmental Protection Agency or any other organization participating

417 in the AQMEII project. This manuscript has been subjected to U.S. EPA review and approved

418 for publication.

419 


\section{References}

421

422 Appel, K.W., Bhave, P.V., Gilliland, A.B., Sarwar, G., Roselle, S.J., 2008. Evaluation of the

423 Community Multiscale Air Quality (CMAQ) model version 4.5: Sensitivities impacting

424 model performance; Part II - particulate matter, Atmospheric Environment 42, 6057-6066.

425

Appel, K.W., Gilliand, A.B., Sarwar, G., Gilliam, R.C., 2007. Evaluation of the Community

427 Multiscale Air Quality (CMAQ) model version 4.5: Sensitivities impacting model

428 performance; Part I - ozone, Atmospheric Environment 41, 9603-9615.

Appel, K. W., Gilliam, R. C., Davis, N., Zubrow, A., and Howard, S. C., 2010. Overview of the Atmospheric Model Evaluation Tool (AMET) v1.1 for evaluating meteorological and air quality models, Environmental Modeling and Software, doi:10.1016/j.envsoft.2010.09.007.

Bey, I., Jacob, D.J., Yantosca, R.M., Logan, J.A., Field, B.D., Fiore, A.M., Li, Q., Liu, H.Y., 435 Mickley, L.J., and Schultz, M.G., 2001. Global modeling of tropospheric chemistry with 436 assimilated meteorology: Model description and evaluation, Journal of Geophysical Research, $437 \quad 106,23073-23096$.

439 Carlton, A. G., Bhave, P. V., Napelenok, S. L., Edney, E. O., Sarwar, G., Pinder, R. W., Pouliot, 440 and G. A., Houyoux, M., 2010. Model representation of secondary organic aerosol in 441 CMAQv4.7, Environmental Science and Technology, 44, 8553-8560. 


\section{Draft - Do not cite or quote}

443 Eder, B., Kang, D., Mathur, R., Pleim, J., Yu, S., Otte, T., and Pouliot, G., 2009. A performance 444 evaluation of the National Air Quality Forecast Capability for the summer 2007, Atmospheric 445 Environment, 43 (14), 2312-2320.

447 Eder, B., Yu, S., 2006. A performance evaluation of the 2004 release of Models-3 CMAQ. $448 \quad$ Atmospheric Environment 40, 4811-4824.

450 Foley, K. M., Roselle, S. J., Appel, K. W., Bhave, P. V., Pleim, J. E., Otte, T. L., Mathur, R., 451 Sarwar, G., Young, J. O., Gilliam, R. C., Nolte, C. G., Kelly, J. T., Gilliland, A. B., and Bash, 452 J. O., 2010. Incremental testing of the Community Multiscale Air Quality (CMAQ) modeling 453 system version 4.7, Geoscientific Model Development 3, 205-226.

455 Grell, G. A., Dudhia, A. J., and Stauffer, D. R., 1994. A description of the Fifth-Generation 456 PennState/NCAR Mesoscale Model (MM5). NCAR Technical Note NCAR/TN-398+STR. 457 Available at http://www.mmm.ucar.edu/mm5/doc1.html.

459 Guenther, A. and Wiedinmyer, C., 2007. User's guide to the Model of Emissions of Gases and $460 \quad$ Aerosols from Nature (MEGAN), Version 2.01.

463 Emission inventory development and processing for the seasonal model for regional air 464 quality, Journal of Geophysical Research, 105 (D7), 9079 - 9090. 
466 Otte, T. L., Pouliot, G., Pleim, J. E., Young, J. O., Schere, K. L., Wong, D. C., Lee, P. C. S.,

467 Tsidulko, M., McQueen, J. T., Davidson, P., Mathur, R., Chuang, H. Y., DiMego, G., and

468 Seaman, N. L., 2005. Linking the Eta model with the Community Multiscale Air Quality

469 (CMAQ) modeling system to build a national air quality forecasting system, Weather and $470 \quad$ Forecasting, 20, 367-384.

471

472 Pleim, J. E, 2007a. A combined local and nonlocal closure model for the atmospheric boundary

473 layer. Part I: model description and testing, Journal of Applied Meteorology and Climate, 46,

$474 \quad 1383-1395$.

475

476 Pleim, J. E., 2007b. A combined local and nonlocal closure model for the atmospheric boundary

477 layer. Part II: application and evaluation in a mesoscale meteorological model, Journal of

478 Applied Meteorology and Climate, 46, 1396-1409.

479

480 Pouliot, G., Pierce, T., van der Gon, H. D., Schapp, M., Moran, M., and Nopmongcol, U., 2011.

481 Comparing emission inventories and model-ready emission datasets between Europe and

482 North America for the AQMEII project, Atmospheric Environment.

483

484 Sakulyanontvittaya, T., Duhl, T., Wiedinmyer, C., Helmig, D., Matsunaga, S., Potosnak, M.,

485 Milford, J., and Guenther, A., 2008. Monoterpene an sesquiterpene emission estimates for the

486 United States, Environmental Science and Technology, 42, 1623-1629.

487 
Schere, K., Flemming, J., Vautard, R., Chemel, C., Colette, A., Hogrefe, C., Bessagnet, B., Meleux, F., Mathur, R., Roselle, S., Hu, R., Sokhi, R. S., Rao, S.T., Galmarini, S., this issue. Trace gas/aerosol boundary concentrations and their impacts on continental-scale AQMEII modeling domains, Atmospheric Environment (this issue).

Skamarock, W. C., Klemp, J. B., Dudhia, J., Gill, D. O., Barker, D. M., Duda, M. G., Huang, XY, Wang, W., and Powers, J. G., 2008. A description of the advanced research WRF version 3. NCAR Tech Note NCAR/TN 475 STR, 125 pp, [Available from UCAR Communications, P.O. Box 3000, Boulder, CO 80307.].

Sofiev, M., Vankevich, R., Lotjonen, M., Prank, M., Petukhov, V., Ermakova, T., Koskinen, J., and Kokkonen, J., 2009. An operational system for the assimilation of satellite information on wild-land fires for the needs of air quality modeling and forecasting. Atmospheric Chemistry and Physics, 9, 6833-6847.

Tesche, T. W., Morris, R., Tonnesen, G., McNally, D., Boylan, J., and Brewer, P. 2006. "CMAQ/CAMx annual 2002 performance evaluation over the eastern US." Atmospheric Environment 40 (26), 4906-4919.

Vautard, R., Moran, M. D., Solazzo, E., Gilliam, R. C., Matthias, V., Bianconi, R., Chemel, C., Ferreira, J., Geyer, B., Hansen, A. B., Jericevic, A., Prank, M., Segers, A., Silver, J. D., Werhahn, J., Wolke, R., Rao, S. T., and Galmarini, S., (this issue). Evaluation of the 
510 meteorological forcing used for the Air Quality Model Evaluation International Initiative

511 (AQMEII) air quality simulations, Atmospheric Environment (this issue).

512

513 Yarwood, G., Roa, S., Yocke, M., and Whitten, G., 2005. Updates to the carbon bond chemical

514 mechanism: CB05. Final report to the US EPA, RT-0400675, available at

515 http://www.camx.com.

516 
518 Table 1. Seasonal, domain-wide MB, ME, NMB and NME for daytime (8am - 8pm LST)

519 average $\mathrm{O}_{3}$ for the North America (NA) AQS network and Europe (EU) AirBase network.

520

\begin{tabular}{|l|l|l|l|l|}
\hline Season & MB (ppb) & NMB (\%) & ME (ppb) & NME (\%) \\
\hline Winter (NA) & -3.5 & -13.4 & 9.0 & 34.7 \\
\hline Winter (EU) & 1.5 & 8.4 & 10.4 & 58.1 \\
\hline & & & & \\
\hline Spring (NA) & -1.8 & -4.1 & 9.3 & 29.4 \\
\hline Spring (EU) & -1.8 & -4.8 & 10.5 & 27.7 \\
\hline & & & & \\
\hline Summer (NA) & 4.4 & 9.8 & 11.0 & 24.2 \\
\hline Summer (EU) & -0.7 & -1.6 & 10.8 & 24.4 \\
\hline & & & & \\
\hline Fall (NA) & 2.6 & 8.4 & 8.8 & 28.0 \\
\hline Fall (EU) & 7.8 & 32.3 & 11.0 & 45.8 \\
\hline
\end{tabular}


523 Table 2. Seasonal, domain-wide MB, ME, NMB and NME for daily average $\mathrm{PM}_{2.5}$ for the North

524 America (NA) AQS network and Europe (EU) AirBase network.

525

\begin{tabular}{|l|l|l|l|l|}
\hline Season & $\mathrm{MB}\left(\mu \mathrm{gm}^{-3}\right)$ & $\mathrm{NMB}(\%)$ & $\mathrm{ME}\left(\mu \mathrm{gm}^{-3}\right)$ & $\mathrm{NME}(\%)$ \\
\hline Winter (NA) & 3.4 & 30.4 & 6.0 & 52.9 \\
\hline Winter (EU) & -12.9 & -55.0 & 15.8 & 67.3 \\
\hline & & & & \\
\hline Spring (NA) & 2.0 & 18.9 & 4.5 & 42.2 \\
\hline Spring (EU) & -5.8 & -36.9 & 8.2 & 52.3 \\
\hline & & & & \\
\hline Summer (NA) & -0.6 & -4.6 & 4.4 & 30.5 \\
\hline Summer (EU) & -4.9 & -37.2 & 6.9 & 52.2 \\
\hline & & & & \\
\hline Fall (NA) & 4.0 & 36.3 & 5.6 & 51.6 \\
\hline Fall (EU) & -3.8 & -24.2 & 7.7 & 49.1 \\
\hline
\end{tabular}

527 
528 Table 3. Seasonal, domain-wide MB, ME, NMB and NME for daily average $\mathrm{PM}_{10}$ for the North

529 America (NA) AQS and Europe (EU) AirBase network.

530

531

\begin{tabular}{|l|l|l|l|l|}
\hline Season & $\mathrm{MB}\left(\mu \mathrm{gm}^{-3}\right)$ & $\mathrm{NMB}(\%)$ & $\mathrm{ME}\left(\mu \mathrm{gm}^{-3}\right)$ & $\mathrm{NME}(\%)$ \\
\hline Winter (NA) & -11.5 & -47.9 & 16.0 & 66.8 \\
\hline Winter (EU) & -21.5 & -64.8 & 23.2 & 69.8 \\
\hline & & & & \\
\hline Spring (NA) & -14.5 & -56.5 & 17.1 & 66.4 \\
\hline Spring (EU) & -14.0 & -56.2 & 15.6 & 59.5 \\
\hline & & & & \\
\hline Summer (NA) & -16.1 & -57.4 & 17.8 & 63.4 \\
\hline Summer (EU) & -15.1 & -61.2 & 16.3 & 66.1 \\
\hline & & & & \\
\hline Fall (NA) & -11.4 & -46.5 & 15.3 & 62.3 \\
\hline Fall (EU) & -12.2 & -46.8 & 15.1 & 57.8 \\
\hline
\end{tabular}

532 


\section{Figure Captions}

534 Fig. 1. Time series of NA daytime (8am - 8pm LST) average ozone (ppb) for AQS observed

535 (black), CMAQ using GEMS (CMAQ-GEMS) data for boundary conditions (dashed; dark grey)

536 and CMAQ using GEOS-Chem (CMAQ-GC) data for boundary conditions (dot-dashed; light

537 grey). The bottom plot shows the corresponding bias (ppb) for the CMAQ-GEMS simulation

538 (solid) and CMAQ-GC simulation (dashed).

540 Fig. 2. Time series of EU daytime (8am - 8pm LST) average ozone (ppb) for AirBase observed

541 (black), CMAQ using GEMS (CMAQ-GEMS) data for boundary conditions (dashed; dark grey)

542 and CMAQ using GEOS-Chem (CMAQ-GC) data for boundary conditions (dot-dashed; light

543 grey). The bottom plot shows the corresponding bias ( $\mathrm{ppb}$ ) for the CMAQ-GEMS simulation

544 (solid) and CMAQ-GC simulation (dashed).

546 Fig. 3. Normalized mean bias (\%) for daytime (8am - 8pm LST) average ozone for the North

547 America AQS (triangles) and NAPS (circles) networks for a) winter b) spring c) summer and d)

548 fall. Warm colors indicate positive NMBs; cool colors indicate negative NMBs; grey shading

549 indicates NMBs less than $\pm 10 \%$.

551 Fig. 4. Normalized mean bias (\%) for daytime (8am - 8pm LST) average $\mathrm{O}_{3}$ for the Europe

552 AirBase (circles), AURN (triangles) and EMEP (squares) networks for a) winter b) spring c)

553 summer and d) fall. Warm colors indicate positive NMBs; cool colors indicate negative NMBs;

554 grey shading indicates NMBs less than $\pm 10 \%$. 


\section{Draft - Do not cite or quote}

556 Fig. 5. Time series of daily average $\mathrm{PM}_{2.5}\left(\mu \mathrm{gm}^{-3}\right)$ for AQS observed (solid) and CMAQ

557 estimated (dashed) for the entire U.S. The bottom time series plot shows the corresponding bias $558\left(\mu \mathrm{gm}^{-3}\right)$

560 Fig. 6. Time series of daily average $\mathrm{PM}_{2.5}\left(\mu \mathrm{gm}^{-3}\right)$ for AirBase observed (solid) and CMAQ

561 estimated (dashed) for Europe. The bottom time series plot shows the corresponding bias $\left(\mu \mathrm{g} \mathrm{m}^{-}\right.$ $\left.5622^{3}\right)$.

564 Fig. 7. Normalized mean bias (\%) for $\mathrm{PM}_{2.5}$ for the North America IMPROVE (circles), CSN 565 (triangles), NAPS (squares) and AQS (diamonds) networks for a) winter b) spring c) summer 566 and d) fall. Warm colors indicate positive NMBs; cool colors indicate negative NMBs; grey 567 shading indicates NMBs less than $\pm 10 \%$.

569 Fig. 8. Normalized mean bias (\%) for $\mathrm{PM}_{2.5}$ for the Europe AirBase (circles), AURN (triangles), 570 and EMEP (squares) networks for a) winter b) spring c) summer and d) fall. Warm colors

571 indicate positive NMBs; cool colors indicate negative NMBs; grey shading indicates NMBs less 572 than $\pm 10 \%$.

574 Fig. 9. Time series of daily average $\mathrm{PM}_{10}\left(\mu \mathrm{gm}^{-3}\right)$ for AQS observed (solid) and CMAQ 575 estimated (dashed) for North America. The bottom plot shows the corresponding bias $\left(\mu \mathrm{gm}^{-3}\right)$.

577 Fig. 10. Time series of daily average $\mathrm{PM}_{10}\left(\mu \mathrm{gm}^{-3}\right)$ for AirBase observed (solid) and CMAQ 578 estimated (dashed) for Europe. The bottom plot shows the corresponding bias $\left(\mu \mathrm{gm}^{-3}\right)$. 


\section{Draft - Do not cite or quote}

580 Fig. 11. Normalized mean bias (\%) for daily average $\mathrm{PM}_{10}$ for the North America AQS network

581 for a) winter b) spring c) summer and d) fall. Warm colors indicate positive NMBs; cool colors

582 indicate negative NMBs; grey shading indicates NMBs less than $\pm 10 \%$.

583

584 Fig. 12. Normalized mean bias (\%) for daily average $\mathrm{PM}_{10}$ for the Europe AirBase (circles),

585 AURN (triangles) and EMEP (squares) networks for a) winter b) spring c) summer and d) fall.

586 Warm colors indicate positive NMBs; cool colors indicate negative NMBs; grey shading

587 indicates NMBs less than $\pm 10 \%$.

588 
Domain-wide Daytime Average Ozone for North America
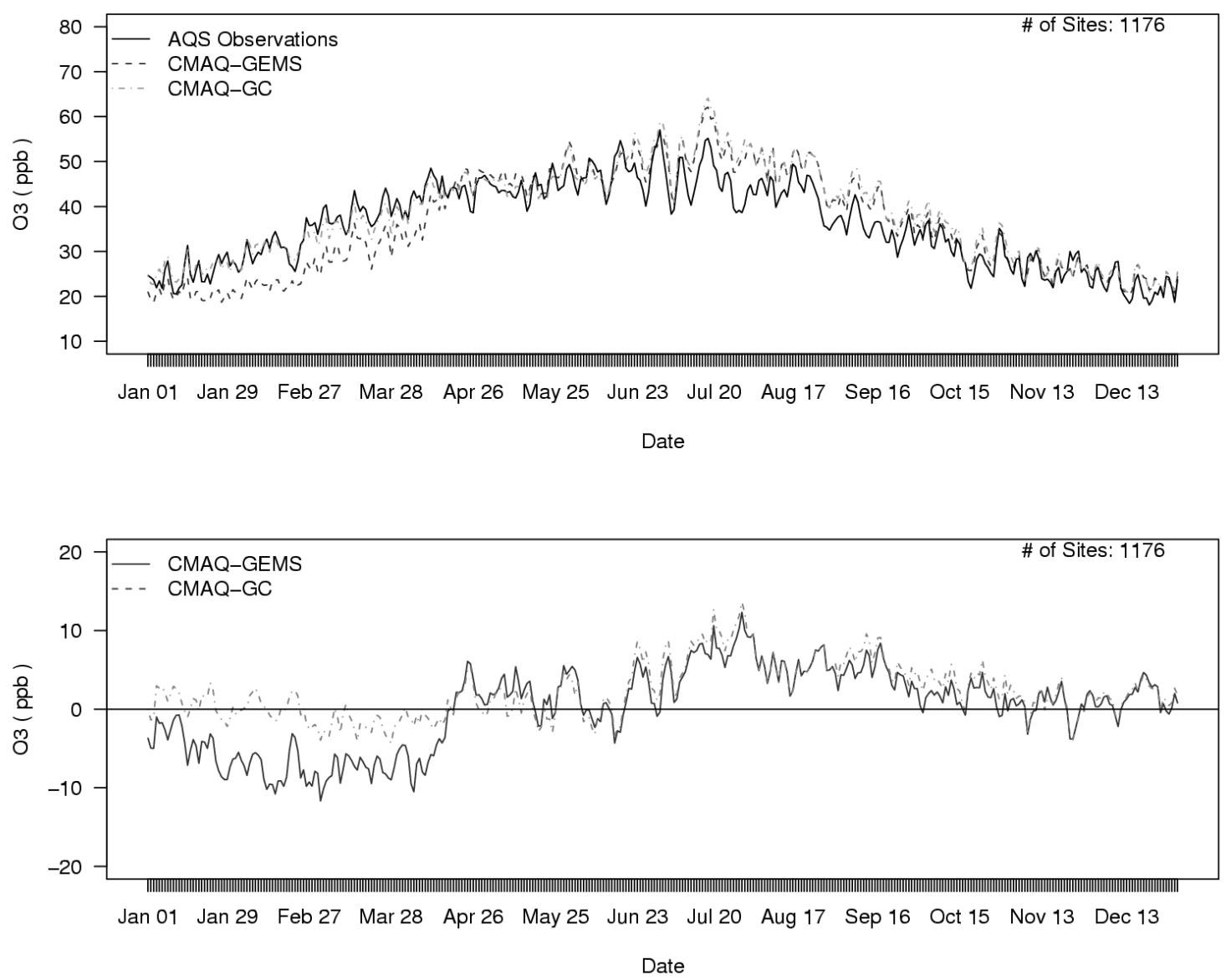

Fig. 1. Time series of NA daytime (8am - 8pm LST) average ozone (ppb) for AQS observed (black), CMAQ using GEMS (CMAQ-GEMS) data for boundary conditions (dashed; dark grey) and CMAQ using GEOS-Chem (CMAQ-GC) data for boundary conditions (dot-dashed; light

594 grey). The bottom plot shows the corresponding bias (ppb) for the CMAQ-GEMS simulation

595

596 (solid) and CMAQ-GC simulation (dashed). 


\section{Domain-wide Daytime Average Ozone for Europe}
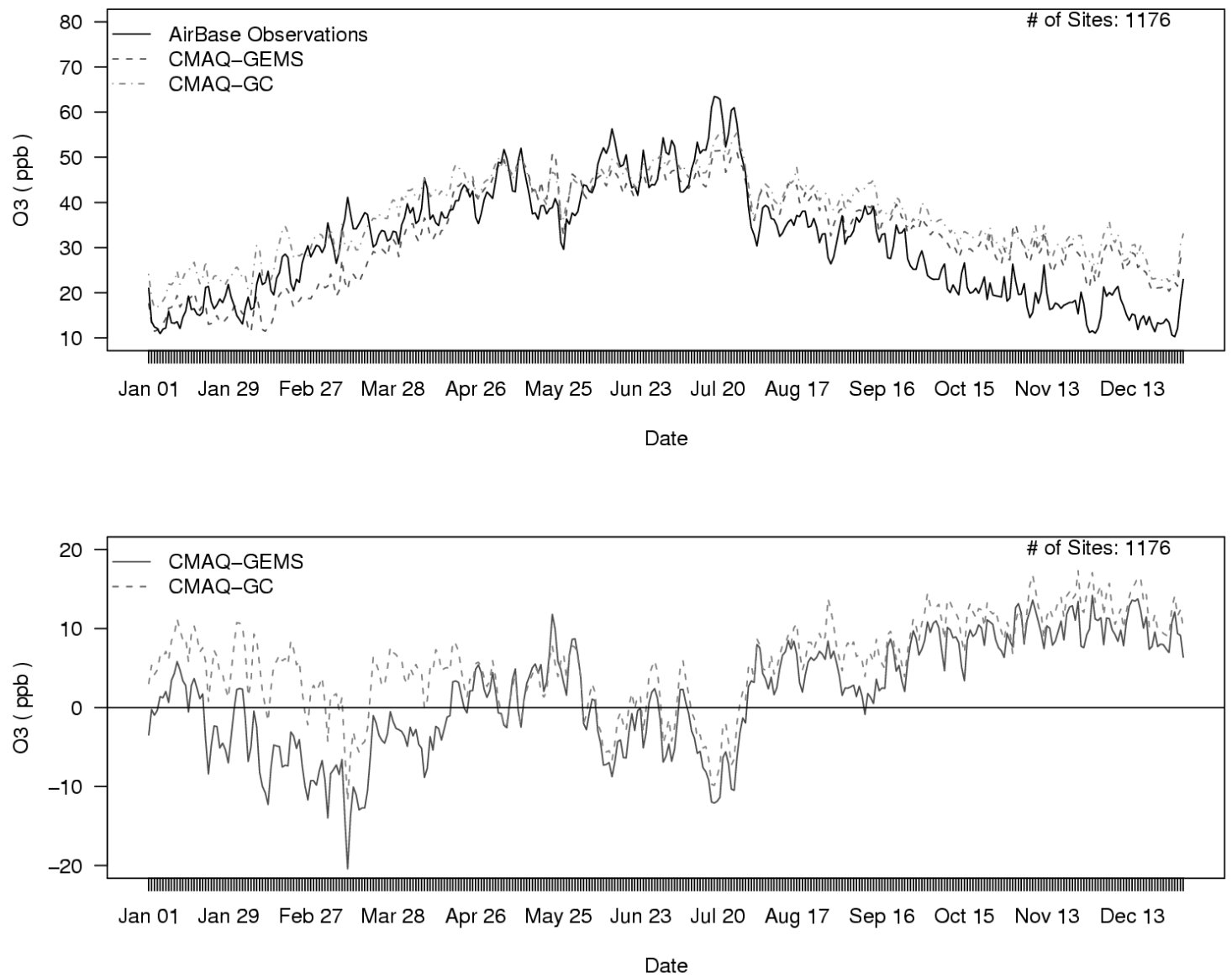

Date

Fig. 2. Time series of EU daytime (8am - 8pm LST) average ozone (ppb) for AirBase observed (black), CMAQ using GEMS (CMAQ-GEMS) data for boundary conditions (dashed; dark grey) and CMAQ using GEOS-Chem (CMAQ-GC) data for boundary conditions (dot-dashed; light

602 grey). The bottom plot shows the corresponding bias (ppb) for the CMAQ-GEMS simulation

603

604 

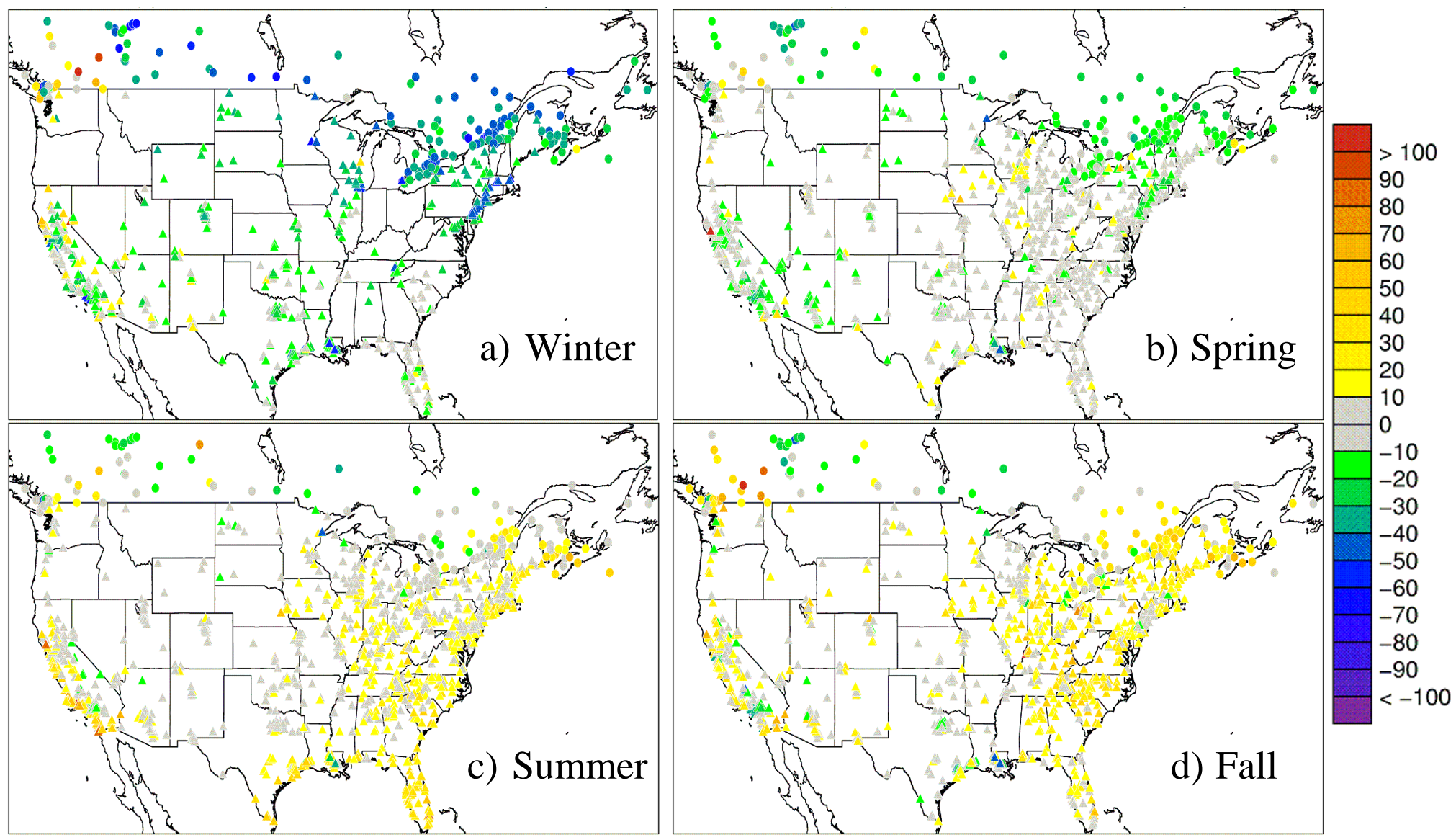

Fig. 3. Normalized mean bias (\%) for daytime (8am - 8pm LST) average ozone for the North America AQS (triangles) and NAPS (circles) networks for a) winter b) spring c) summer and d) fall. Warm colors indicate positive NMBs; cool colors indicate negative NMBs; grey shading indicates NMBs less than $\pm 10 \%$. 


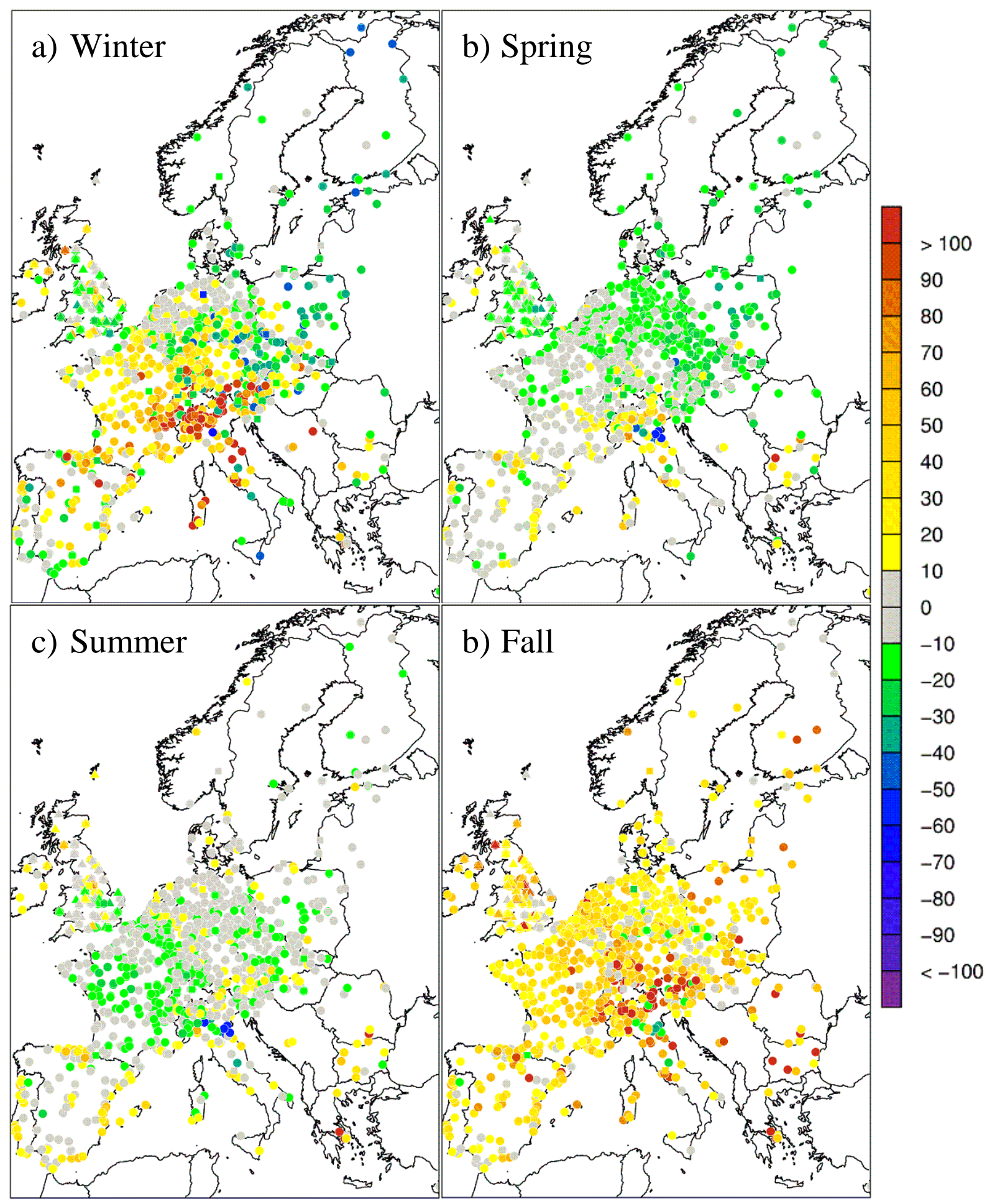

Fig. 4. Normalized mean bias (\%) for daytime (8am - 8pm LST) average $\mathrm{O}_{3}$ for the Europe AirBase (circles), AURN (triangles) and EMEP (squares) networks for a) winter b) spring c) summer and d) fall. Warm colors indicate positive NMBs; cool colors indicate negative NMBs; grey shading indicates NMBs less than $\pm 10 \%$. 

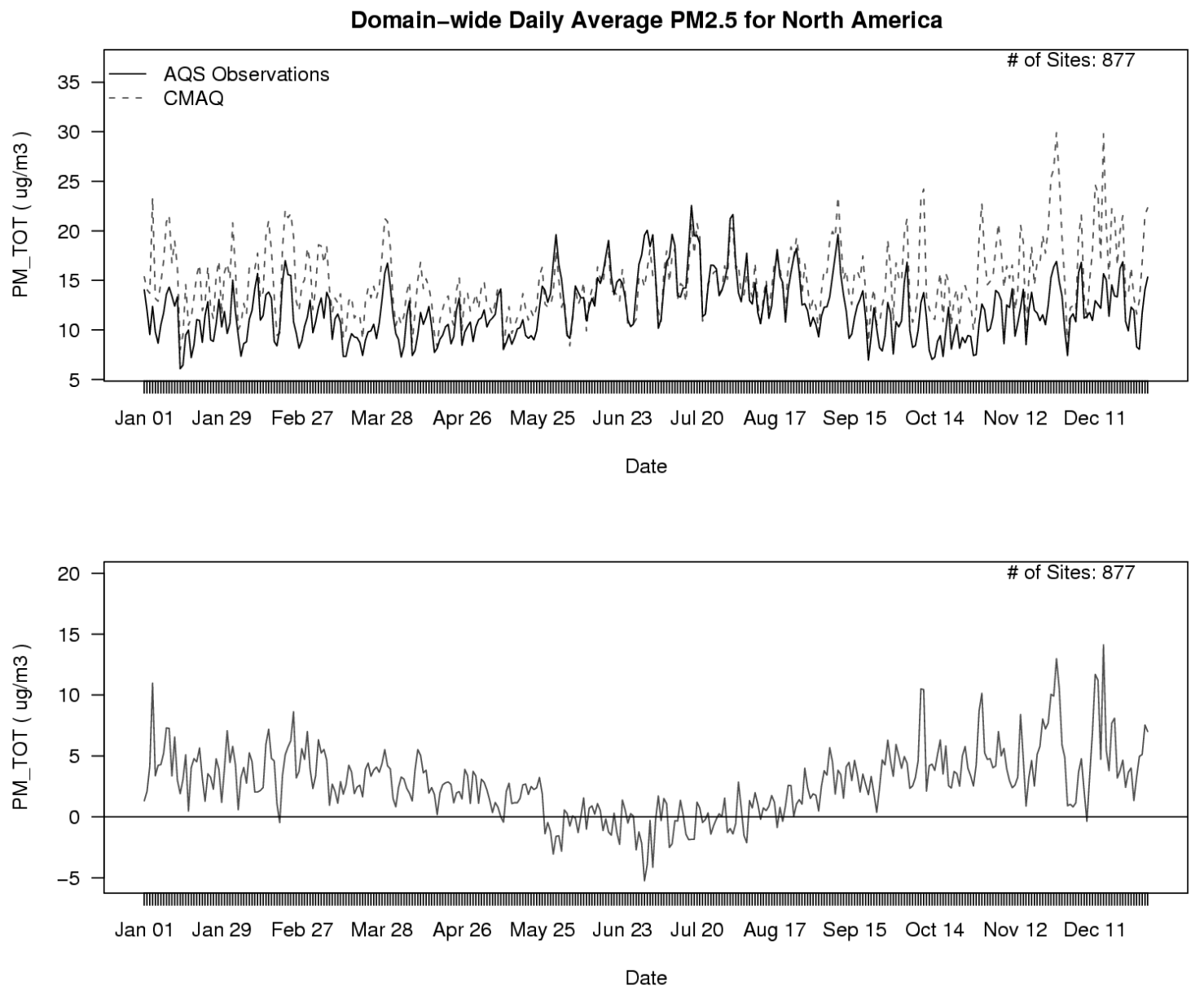

608

609

610

611

612
Fig. 5. Time series of daily average $\mathrm{PM}_{2.5}\left(\mu \mathrm{gm}^{-3}\right)$ for AQS observed (solid) and CMAQ estimated (dashed) for the entire U.S. The bottom time series plot shows the corresponding bias $\left(\mu \mathrm{gm}^{-3}\right)$. 
Domain-wide Daily Average PM2.5 for Europe
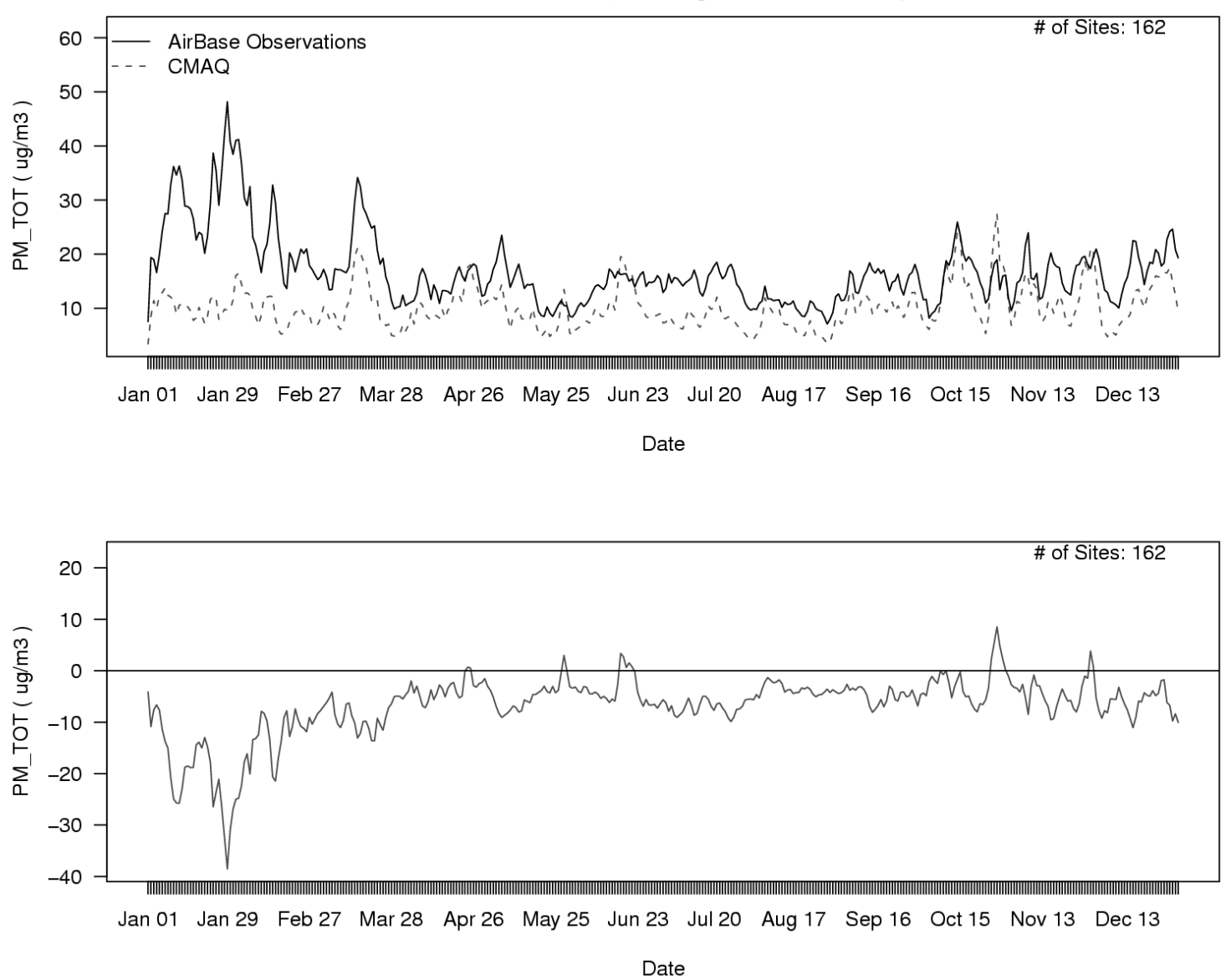

613

614 Fig. 6. Time series of daily average $\mathrm{PM}_{2.5}\left(\mu \mathrm{gm}^{-3}\right)$ for AirBase observed (solid) and CMAQ 615 estimated (dashed) for Europe. The bottom time series plot shows the corresponding bias $\left(\mu \mathrm{g} \mathrm{m}^{-}\right.$ $\left.616^{3}\right)$.

617

618 

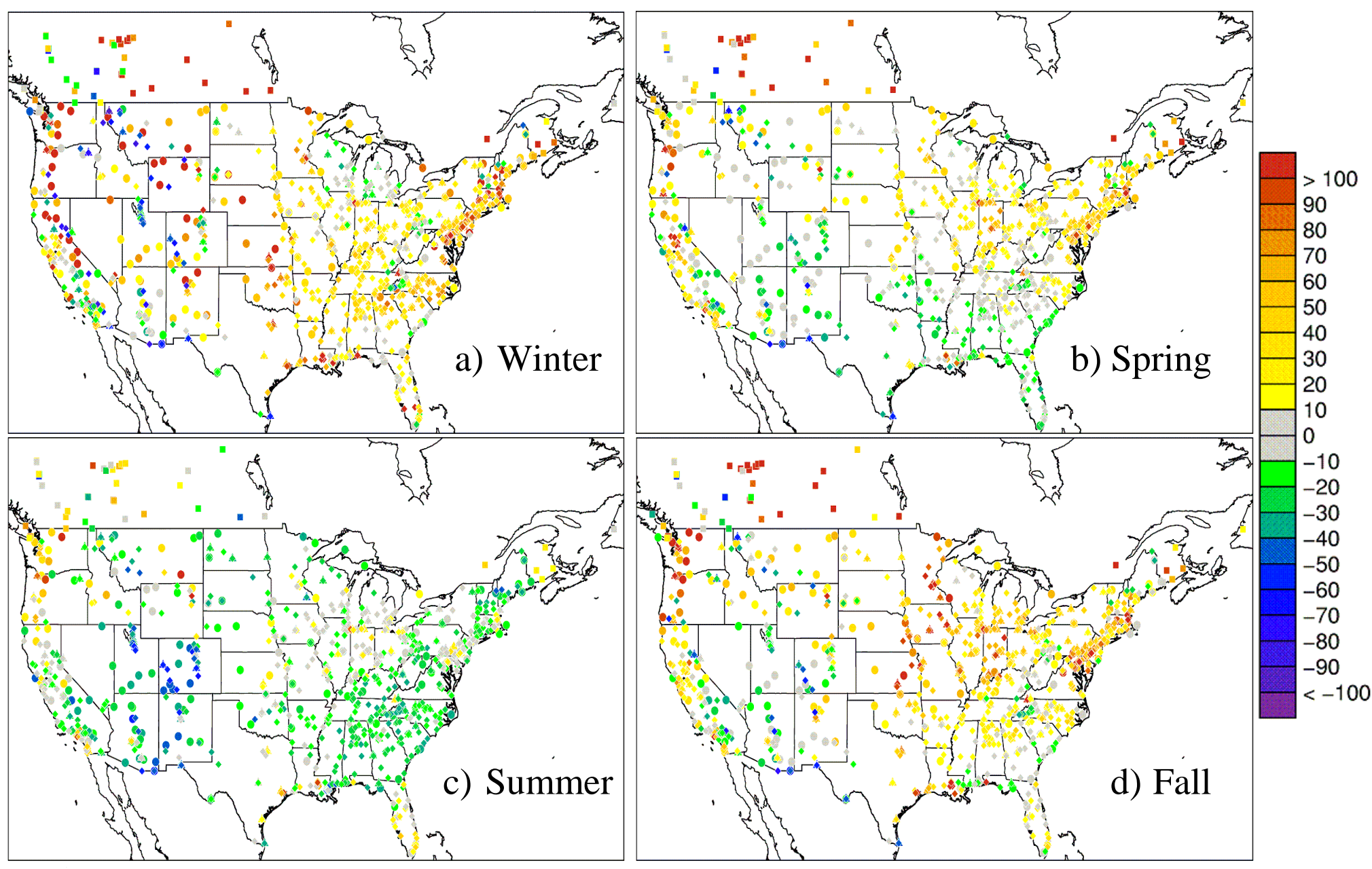

Fig. 7. Normalized mean bias (\%) for $\mathrm{PM}_{2.5}$ for the North America IMPROVE (circles), CSN (triangles), NAPS (squares) and AQS (diamonds) networks for a) winter b) spring c) summer and d) fall. Warm colors indicate positive NMBs; cool colors indicate negative NMBs; grey shading indicates NMBs less than $\pm 10 \%$. 


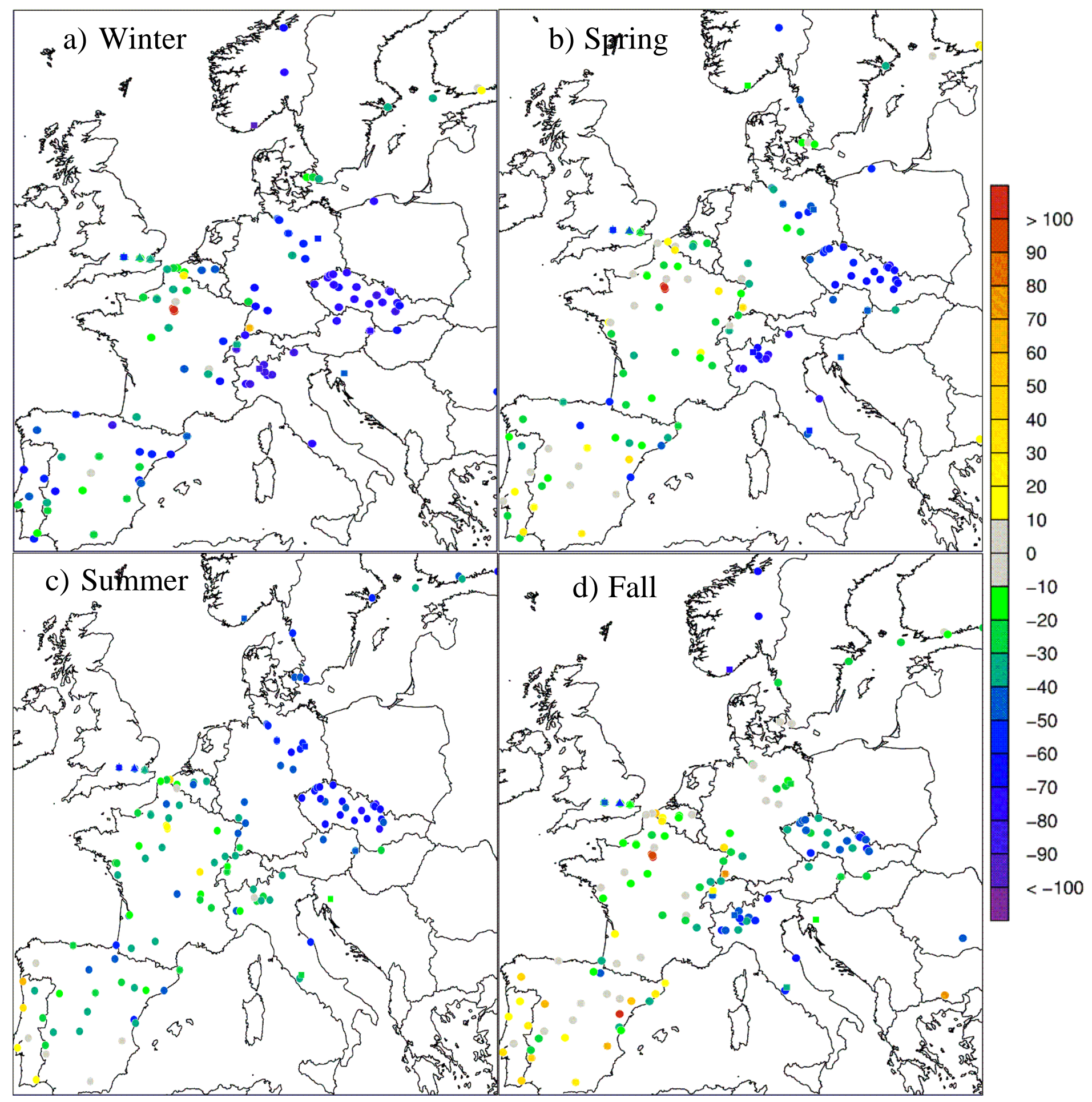

Fig. 8. Normalized mean bias (\%) for $\mathrm{PM}_{2.5}$ for the Europe AirBase (circles), AURN (triangles), and EMEP (squares) networks for a) winter b) spring c) summer and d) fall. Warm colors indicate positive NMBs; cool colors indicate negative NMBs; grey shading indicates NMBs less than $\pm 10 \%$. 


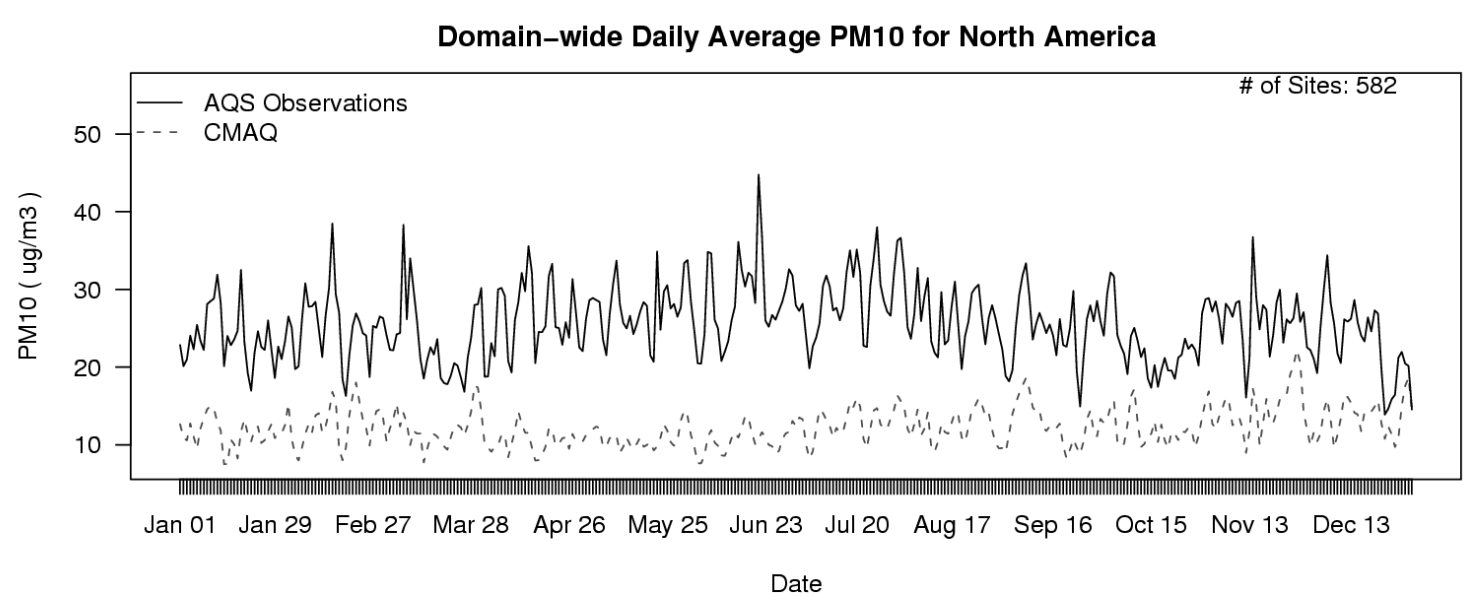

623

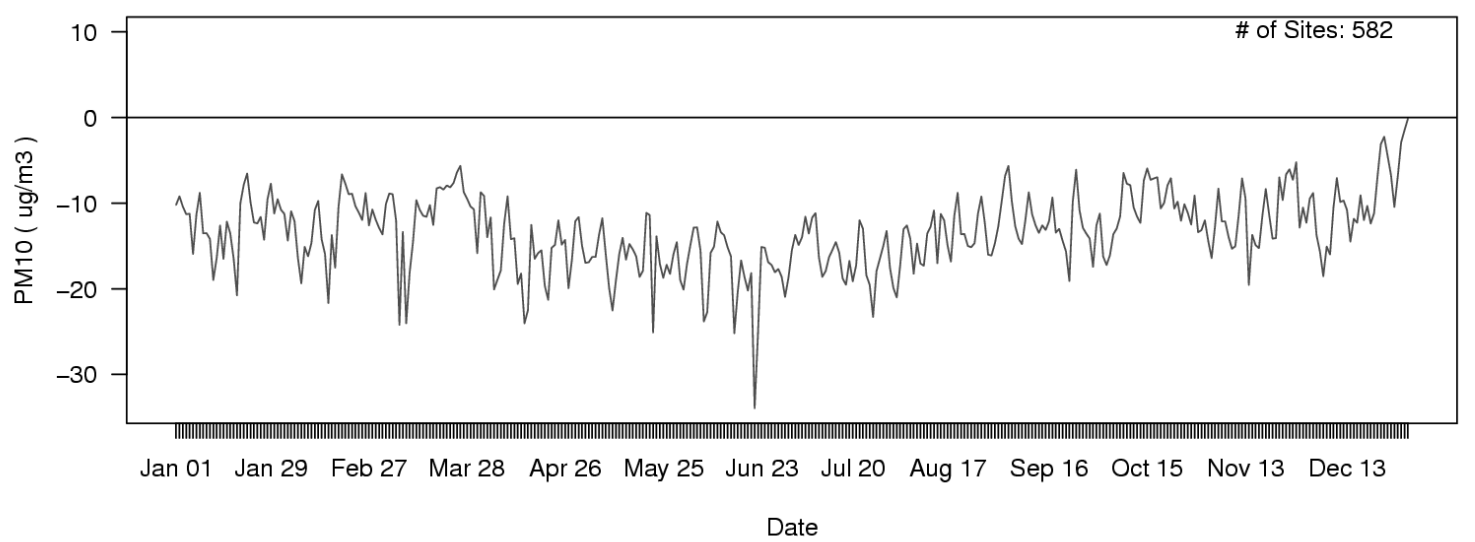

Fig. 9. Time series of daily average $\mathrm{PM}_{10}\left(\mu \mathrm{gm}^{-3}\right)$ for $\mathrm{AQS}$ observed (solid) and CMAQ 626 estimated (dashed) for North America. The bottom plot shows the corresponding bias $\left(\mu \mathrm{gm}^{-3}\right)$. 


\section{Domain-wide Daily Average PM10 for Europe}
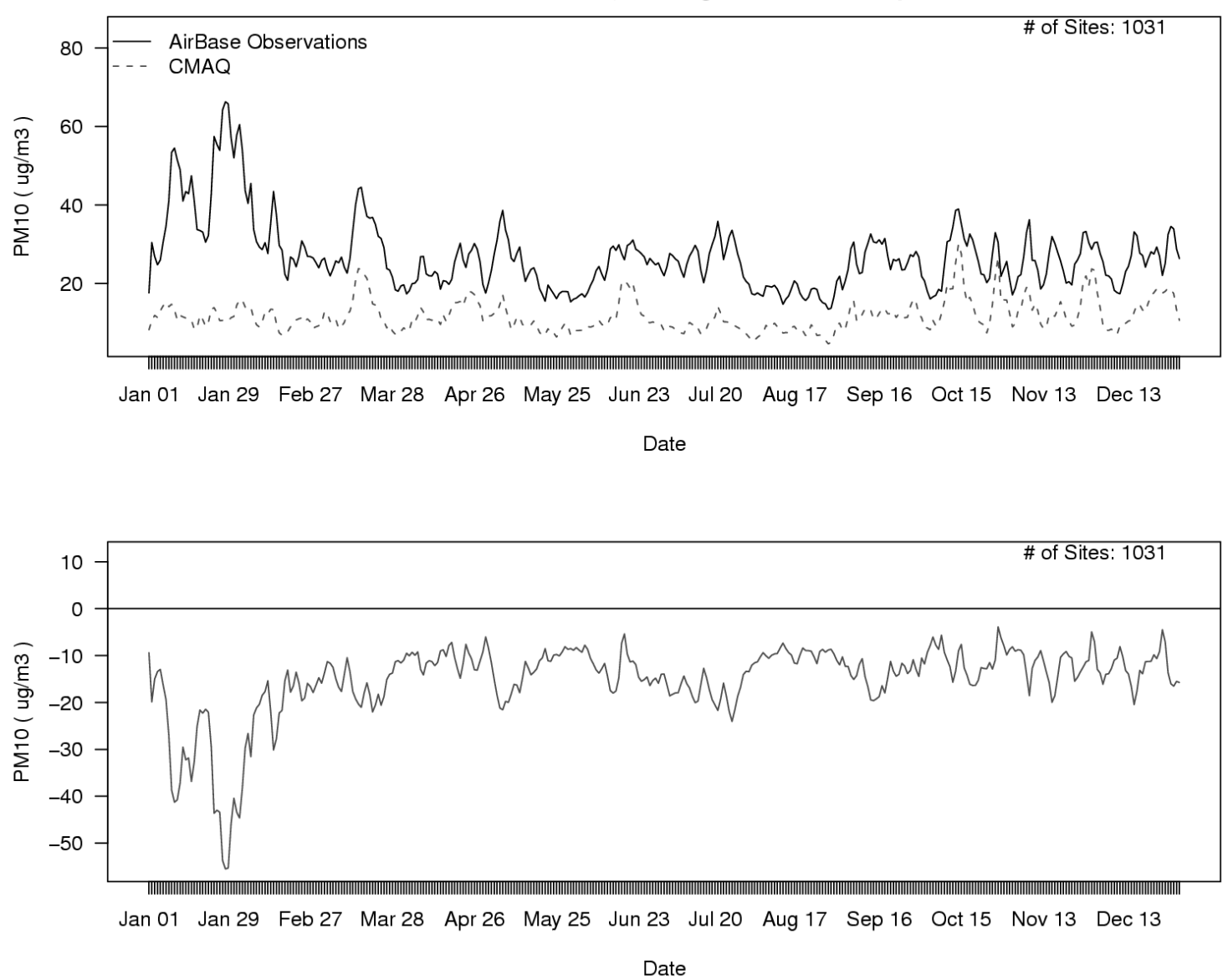

627

Fig. 10. Time series of daily average $\mathrm{PM}_{10}\left(\mu \mathrm{gm}^{-3}\right)$ for AirBase observed (solid) and CMAQ estimated (dashed) for Europe. The bottom plot shows the corresponding bias $\left(\mu \mathrm{gm}^{-3}\right)$. 


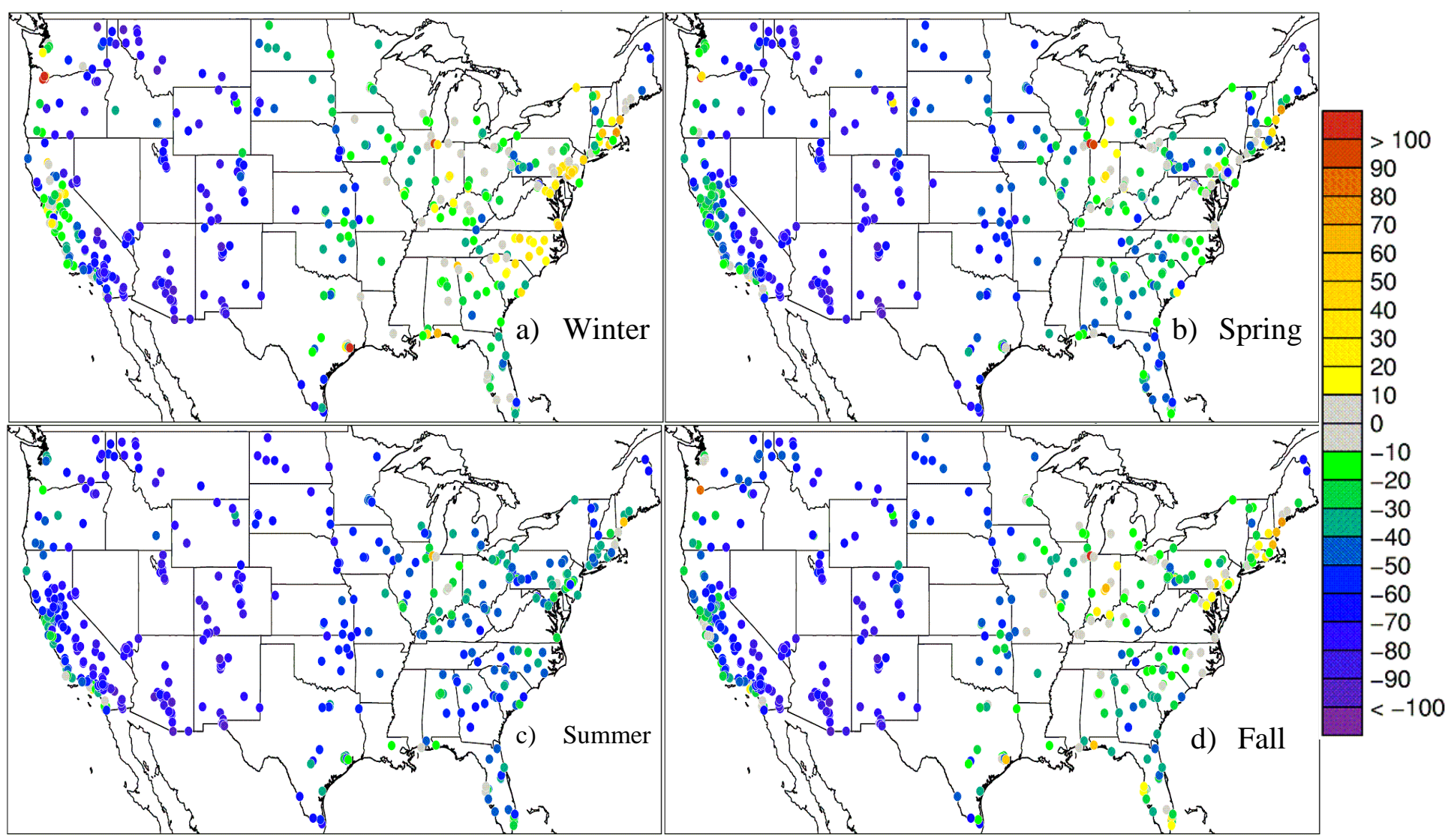

Fig. 11. Normalized mean bias (\%) for daily average $\mathrm{PM}_{10}$ for the North America AQS network for a) winter b) spring c) summer and d) fall. Warm colors indicate positive NMBs; cool colors indicate negative NMBs; grey shading indicates NMBs less than $\pm 10 \%$. 


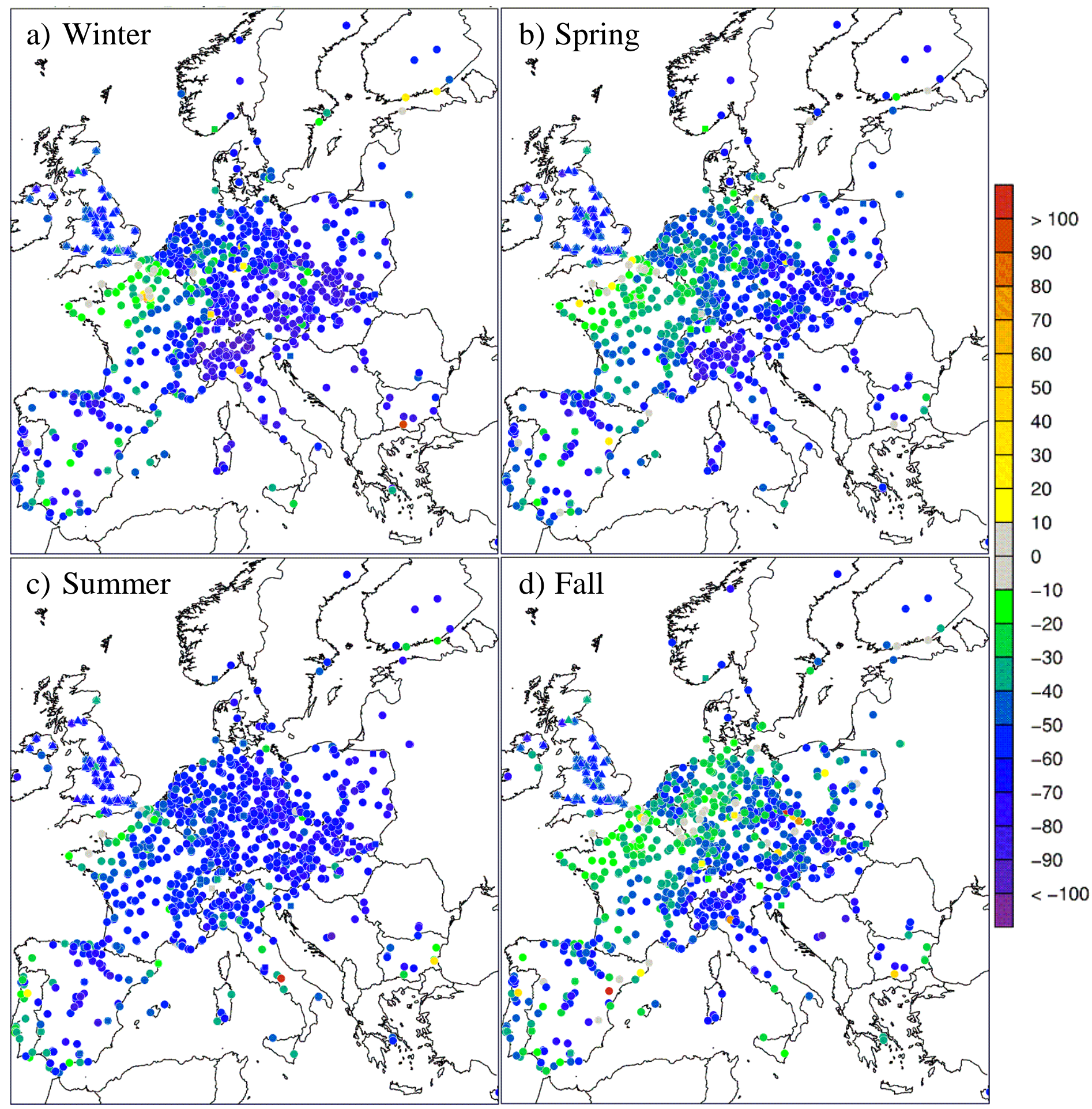

Fig. 12. Normalized mean bias (\%) for daily average $\mathrm{PM}_{10}$ for the Europe AirBase (circles), AURN (triangles) and EMEP (squares) networks for a) winter b) spring c) summer and d) fall. Warm colors indicate positive NMBs; cool colors indicate negative NMBs; grey shading indicates NMBs less than $\pm 10 \%$. 